\title{
A construção atitudinal de crianças em situação de diferença-diversidade em escolas primárias francesas: uma abordagem transcultural
}

\author{
The construction of children's attitudes in difference-diversity situations in \\ French Elementary Schools: a transcultural approach \\ Eric Brun* \\ Universidade do Estado da Babia, Alagoinhas, Bahia, Brasil
}

\begin{abstract}
Resumo: Este artigo apresenta resultados obtidos numa pesquisa comparativa longitudinal realizada em seis turmas de escolas públicas francesas entre 2012 e 2015 do último ano da Educação Infantil ao $1^{\mathrm{o}}$ ano do Ensino Fundamental I no intuito de observar a evolução das tendências alteritáriasetnocêntricas das crianças através dos seus discursos e dos discursos das suas professoras dentro da implementação de um projeto intervencionista e colaborativo de "Despertar para as línguas" (grupos experimentais) e sem projeto particular (grupos de controle). O objetivo final foi verificar o impacto real que uma abordagem do tipo "Despertar para as línguas" focalizada essencialmente nas competências interculturais e atitudinais pode ter sobre a aprendizagem de uma língua estrangeira moderna no final do $1^{\circ}$ ano do Ensino Fundamental I.
\end{abstract}

Palavras chave: Ensino de línguas e culturas. Atitudes. Alteridade. Transculturalidade. Línguas estrangeiras modernas.

\begin{abstract}
This article presents the results of a comparative longitudinal research carried out in six classes of French public schools from 2012 to 2015 (5-7 years old) in order to observe the evolution of children's alterity-ethnocentric tendencies through their speeches and those of their teachers as part of the implementation of an interventionist and collaborative project of Languages Awakening (experimental groups) and without any specific project (control groups). The final objective was to verify the real impact that a Languages Awakening Approach based on intercultural and attitudinal skills might have on foreign language learning.
\end{abstract}

Keywords: Languages and Cultures Teaching. Attitudes. Alterity. Transculturality. Modern foreign languages.

\section{INTRODUÇÃO}

Este artigo apresenta as tendências alteritárias-etnocêntricas de crianças matriculadas em seis escolas públicas francesas (Educação Infantil e Ensino Fundamental I) nos departamentos Var e Bouches du Rhône. Os resultados apresentados foram obtidos em uma pesquisa comparativa e longitudinal realizada entre 2012 e 2015 (ÉRIC BRUN, 2015). Esta pesquisa objetivou compreender a evolução das atitudes das crianças e das suas professoras perante a diferença através da expressão oral antes e durante a aprendizagem de uma língua estrangeira moderna. A pesquisa foi iniciada no último ano da Educação Infantil, no começo do ano letivo 2012-2013, com seis turmas de três escolas distintas, com um efetivo total de 155 alunos e 6 professoras. Prosseguiu no ano seguinte no $1^{\circ}$ ano do Ensino

\footnotetext{
* Doutor em Ciências da Linguagem, Université d'Aix-Marseille, Professor Assistente de Língua e Literatura Francesas do Departamento de Educação, Campus II, Universidade Estadual da Bahia, Salvador, Bahia, Brasil, e-brun@hotmail.com.
} 
Fundamental I (2013-2014) com as mesmas turmas e foi finalizada no decorrer do $2^{\circ}$ ano (2014-2015). O objetivo principal foi aprofundar a análise da influência direta e indireta de uma abordagem educativa do tipo Despertar para as linguas (Michel CANDELIER et al., 2003a; 2003b) na competência alteritária, e por corolário, na aprendizagem de uma língua estrangeira moderna. A pesquisa comparou os resultados obtidos com as turmas que participaram do projeto Despertar para as línguas (quatro turmas no departamento $V$ ar) e com aquelas que não participaram (duas turmas no departamento Bouches du Rhône). O objetivo específico era descobrir a rede de atitudes alteritárias-etnocêntricas das crianças e de suas professoras através da análise das gravações dos discursos produzidos coletivamente em sala de aula no decorrer de dois tipos de sequências pedagógicas: uma sequência específica do projeto Despertar para as línguas (apenas para as turmas experimentais) e uma sequência de leitura-debate (para os dois tipos de turmas). Uma terceira ferramenta de pesquisa audiovisual foi elaborada para coletar, individualmente, as escolhas das crianças no decorrer deste período trienal diante de situações potencialmente discriminantes.

Este projeto que passamos a nomear Despertar para as linguas-culturas do mundo (para lembrar a importância do par conceitual e da diversidade infinita) visava à implantação de uma educação para a diversidade linguística-cultural apoiando-se, primeiramente, no reconhecimento e na valorização das línguas-culturas das crianças e, em seguida, numa colaboração estreita com as famílias que possuíam uma ou várias línguas-culturas. O objetivo do projeto educativo foi fazer com que as crianças descobrissem as línguas-culturas umas das outras, incluindo a língua da escolaridade (o francês) e as línguas regionais, dentro de uma abordagem explicitamente antidiscriminante. O projeto Despertar para as línguas-culturas do mundo não teve como objetivo a aprendizagem formal de uma só língua, divergindo assim, da abordagem singular totalmente centrada no ensino do inglês, caso frequente na escola francesa visto que a escolha do ensino do inglês teve um crescimento exponencial e hegemônico passando de 25\% em 2001-2002 para 99\% em 20152016 (Ministério da Educação Nacional, 2016, p.74). O projeto Despertar para as linguas-culturas do mundo concebe as línguas modernas a partir de uma abordagem plural das línguas-culturas por expor às crianças toda a riqueza da diversidade (MICHEL CANDELIER, 2012, p. 6) que lhes é apresentada, antes de mais nada, sob uma forma visual, através de um locutor de outra língua-cultura e membro da família da criança, (aparência e expressões posturais-miméticasgestuais), e sonora (línguas faladas e fonemas produzidos).

Esta abordagem didática se apoia essencialmente na diversidade presente na turma e nas competências linguístico-culturais das famílias que são convidadas a participar ativamente das descobertas das crianças sob a orientação e a gestão da professora. Ela passa pela criação (ainda a ser concebida) de uma ligação ativa e cooperativa entre a escola e a família na qual os pais não são simples executores. É frequente que a participação da família ainda seja "pensada pelos atores escolares como uma ferramenta de educação das famílias" (FRÉDÉRIQUE GIULIANI, JEAN-PAUL PAYET, 2014, p. 8). Um locutor membro da família substitui então a professora, ao longo de uma sessão, no seu papel de saber, humanizando e possibilitando, com sua presença, a conscientização da necessidade da 
aprendizagem de Línguas estrangeiras modernas pelas crianças. Este processo é sociodidático por definição na medida em que seus "princípios são de ligar ensino de línguas e práticas de linguagem sociais, levando em conta as competências plurilingues dos locutores para lhes dar valor nos processos didáticos" (STÉPHANIE CLERC, 2008, p.195). Mas esta presença consolida igualmente a autoestima da criança em relação à sua professora, às outras crianças do grupo e às outras crianças da escola. O projeto Despertar para as linguas-culturas do mundo almeja então, essencialmente e por princípio, (desde a Educação Infantil) a aprendizagem de uma competência atitudinal alteritária que vai gerar, por sua vez, uma apetência fonético-fonológica (diversas atividades com onomatopeias são propostas no livro didático “As línguas do mundo no quotidiano” de Martine Kervran, 2012), mas também a intonação expressiva global. A Educação infantil e os dois primeiros anos do Fundamental I são propícios para esta abordagem da diversidade através da (re)construção das atitudes positivas pois: "entre 4 e 7 anos, ocorrem representações, sistemas de valores e de expectativas de comportamento que, por conseguinte, se tornam tão automáticos que acabam constituindo uma segunda natureza, sendo assim dificeis de serem captados" (Maroussia Raveaud, 2006, p. 5).

\section{ABORDAGEM METODOLÓGICA DE INVESTIGAÇÃO DAS TENDÊNCIAS ALTERITÁRIAS-ETNOCÊNTRICAS DAS CRIANÇAS}

\subsection{A FERRAMENTA DE COLETA DE DADOS: A SESSÃO DE LEITURA- DEBATE}

A sessão de leitura-debate foi então a ferramenta coletiva de coleta de dados comum aos grupos experimentais e de controle (sem envolvimento dos familiares). Os resultados obtidos provêm de interações verbais significativas das crianças e das professoras observadas e gravadas durante as duas sessões anuais de leituradebate realizadas no último ano da Educação Infantil e no primeiro ano do Ensino Fundamental I com as mesmas turmas. As sessões de leitura-debate realizadas pela professora consistiam na leitura de dois livros que haviam sido anteriormente selecionados em conjunto com as equipes pedagógicas das escolas. Os critérios de seleção dos livros privilegiaram principalmente as narrações, as ilustrações e as mensagens antidiscriminantes claras. Essas duas sessões de leitura-debate foram realizadas da mesma forma no início e no fim do ano escolar no último ano da Educação Infantil e novamente no primeiro ano do Ensino Fundamental I em seis turmas (aproximadamente 155 crianças). A repetição desta atividade teve como finalidade analisar a evolução dos debates de um ano para o outro entre as turmas experimentais e as turmas de controle a partir de um mesmo conteúdo textual e ilustrado. Apenas a narradora, ou seja, a professora, mudava de um ano para outro. Cada professora se comprometia a seguir o mesmo procedimento de leitura em conformidade com o protocolo de pesquisa que objetivava homogeneizar a narração. Contudo, foi extremamente difícil agir da mesma maneira na gestão dos debates que variavam significativamente de uma professora para outra. As 
interações verbais significativas geradas durante a sessão de leitura-debate foram todas aquelas que traziam posicionamentos atitudinais em face da discriminação. Os posicionamentos foram organizados segundo três tendências: neutra (ausência de posicionamento claro), não discriminante e discriminante, e foram expressos de diversas maneiras: diálogos com a professora, monólogos ou exclamações que se assemelhavam muitas vezes com um diálogo sem interlocutor determinado. Eis aqui um exemplo de uma interação verbal significativa ${ }^{1}$ ocorrida em uma turma do último ano da Educação Infantil, classificada como tendência discriminante:

(A professora pergunta às crianças se elas haviam gostado do livro narrado "O homem de cor'):

- Maël: Não gostei não.

- Professora: Então diga por quê, você tem direito, mas precisa dizerer por quê.

- Maël (responde após ter ostensivamente olhado para o lado da sala para saber onde estava o educador assistente que era negro): Porque tinha um bomem preto $^{2}$.

Trata-se de "tendência" discriminante nesta troca por significar que todo discurso infantil pode ser levado a evoluir (ou não) ao longo de sua educação escolar e de sua educação familiar. Esses discursos devem ser considerados na sua instantaneidade ao longo das atividades pedagógicas realizadas em sala, mas devem também ser igualmente levados em conta a médio prazo na escala do ano escolar para podermos apreciar a ancoragem (consolidação de uma tendência discriminante) ou a metamorfose (desconstrução desta tendência).

\subsection{OS SUPORTES DIDÁTICOS DAS SESSÕES DE LEITURA-DEBATE}

Se a literatura francesa ilustrada para as crianças jovens pautadas no tema da diversidade e das discriminações apresenta com frequência uma clara intenção educativa antidiscriminante, ela o faz de forma interativa a partir de uma longa tradição semântica histórica já discriminante. De fato, em dez livros analisados sobre esta temática, oito foram rejeitados em função de ambivalências profundas nas mensagens educativas veladas como em Le voyage de Solo (MIRIAM KOCH, 2008) ou dos meios utilizados como em L'xuf du coq (HUBERT BEN KEMOUN, BRUNO HEITZ, 2005). O primeiro livro selecionado e lido, Homme de couleur (JÉRÔME RUILLIER, 2011), apresenta de forma binária duas crianças, uma branca e outra negra, para ilustrar expressões idiomáticas francesas (azul de frio, verde de medo, etc.) e sobretudo para invalidar, como conclusão, o título Homme de couleur (Homem de cor). Ainda que a intenção educativa seja louvável, em uma abordagem literária da diversidade, ela se apoia no reforço de uma expressão idiomática discriminante exclusivamente adulta e absolutamente obscura para crianças jovens. Deve-se notar, aliás, que as capacidades de compreensão das crianças estão não apenas em defasagem em relação aos conteúdos literários, mas

\footnotetext{
${ }^{1}$ Os diálogos foram traduzidos pelo autor (nomes fictícios, manutenção da linguagem coloquial das professoras e das hipóteses gramaticais e escolhas lexicais das crianças).

${ }^{2}$ Em francês o adjetivo noir utilizado pela criança pode fazer referência tanto à cor preta quanto à etnia do personagem (não havendo a distinção do português preto/negro).
} 
também em relação aos discursos das professoras que recorrem frequentemente a conceitos abstratos adultos. No entanto, o que se intencionava nessas sessões de leitura-debate era, antes mais nada, a verbalização de atitudes pessoais das crianças e em seguida a confrontação coletiva ao longo dos debates entre elas e a professora. A segunda obra, Des amis de toutes les couleurs (Amigos de todas as cores), (CATHERINE DOLTO, COLLINE FAURE-POIRÉE, 2009) oferece a vantagem de situar a história em contexto escolar plural, ou seja, em uma situação real ou percebida de diversidade linguístico-cultural, e de evocar a origem biológica da diversidade fenotípica abordando as diferentes cores de pele e de cabelos. No entanto, aqui ainda a defasagem semântica evocada anteriormente reaparece através da utilização de expressões idiomáticas metafóricas que definem de forma ambivalente uma cor de pele (pele acobreada, cor de pão de mel, etc.) e de certa maneira se contrapõem a uma abordagem plural antidiscriminante. Esta marca linguística é tão forte que é possível encontrá-la sob forma de lapso ou de automatismos nos discursos conscientemente não discriminantes da maioria das professoras desta pesquisa, como mostra a seguinte troca ocorrida na turma do último ano da Educação Infantil e que não é um caso isolado ou excepcional:

\footnotetext{
Professora: E o beberinho que tem a pele rosa, quando ele crescer, ele será...?

Grupo: Branco!!

Professora: Ele fica branco, a pele branca, como vocês... como alguns de vocês, como os que levantaram a mão.
}

Argentine: Mas a gente, mas eu, a gente não é branco, branco, branco!

A autocorreção imediata da professora é um aspecto fundamental no longo processo de desconstrução e de tomada de consciência dos hábitos linguísticos discriminantes a serem rejeitados e combatidos. A poderosa influência do discurso da professora sobre as atitudes da criança foi confirmada através dos resultados quase análogos das tendências alteritárias-etnocêntricas observadas no discurso das crianças e das suas professoras.

\section{ALGUNS RESULTADOS DAS TENDÊNCIAS ALTERITÁRIAS- ETNOCÊNTRICAS DAS CRIANÇAS}

\subsection{SOBRE AS INTERAÇÕES VERBAIS SIGNIFICATIVAS}

Se a criança de 5 a 6 anos dialoga comumente com a professora designandoa nitidamente nessa intenção de comunicação através de um "Madame" (forma de tratamento formal), em geral, ela não procede da mesma maneira com outra criança da sua turma até mesmo quando ela reage a um comentário que exige dela um certo posicionamento. As causas são complexas pois elas parecem estar submetidas à alternância de diversos parâmetros. Elas representam, às vezes, uma medida de proteção da autoimagem da criança quando ela parece não querer ou não poder se posicionar "contra" alguém. Esta noção de imagem social é reencontrada no conceito de "autoimagem” que, para Christa Preissing (2006, p.15, nossa tradução): "não é apenas desenhada pelos outros. A autoimagem é a criança que a cria para ela mesma. E, 
no entanto, ela é claramente influenciada pela imagem que os outros criaram dela. É um processo individual e, no entanto, ligado ao olhar dos outros". As causas parecem ser também a tradução de um não reconhecimento da legitimidade do discurso de outra criança. Mas, elas podem proceder, às vezes, de uma certa ingenuidade cognitiva quando a mensagem é interpretada de forma errônea como no diálogo já evocado anteriormente, finalizado por Louka da seguinte maneira:

(A professora pergunta às crianças se elas haviam gostado do livro narrado " $O$ homem de cor $\left.^{2}\right)$ :

- Maël: Não gostei não.

- Professora: Então diga por quê, você tem direito, mas precisa dižer por quê.

- Maël (responde após ter ostensivamente olhado para o lado da sala para saber onde estava o educador assistente que era negro): Porque tinha um homem preto.

- Louka: Eu adoooro o preto!

De toda maneira, o que domina finalmente neste tipo específico de interação verbal com crianças parece ser a rara empatia em situação de conflito ou sofrimento físico ou psicológico por parte das crianças em relação à criança que está possivelmente em sofrimento simbólico ou real. $\mathrm{Na}$ interação seguinte, a professora mostra a ilustração do livro para a sua turma do último ano de Educação Infantil (5 anos):

Figure 1 - Casal com nacionalidades diferentes

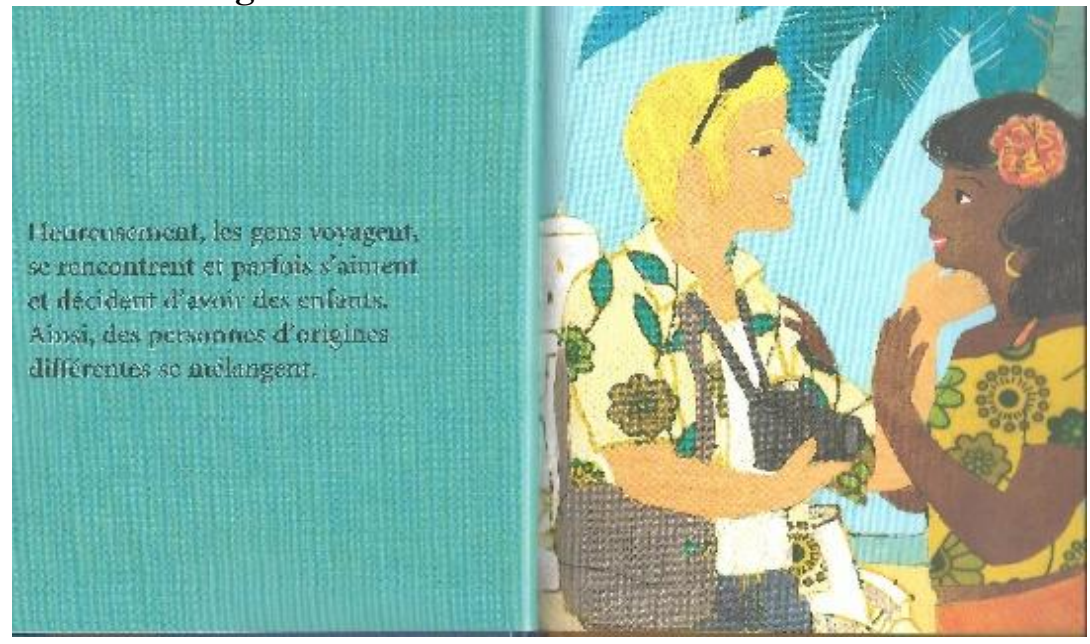

Fonte: Dolto, Faure-Poirée, 2009, p.7-8

- Professora: Será que o papai vai se tornar negro e a mamãe branca?

- Grupo: Não!!

- Professora: Porém, o que vai acontecer? (silêncio do grupo)... quando eles tiverem um bebê?

- Ethan: Eu sei! Primeiro, precisa ir para o hospital!

- Professora: E como será o bebê quando nascer?

- Abdelaziz: Pequeno!

A professora obtém, assim, respostas lógicas, objetivas e desprovidas de qualquer compreensão dos implícitos contidos na sua pergunta. É possível 
reencontrar nas próximas interações uma variante semântica da inadequação entre o discurso adulto e a capacidade de compreensão infantil:

- Professora: $E$ os franceses vão dizer para ele... você é de origem...

- Quentin: Evocê é estrangeiro... estrangeira.

- Professora: O que significa quando a gente é de uma "origem" estrangeira"?

- Kenzo (muito seriamente): Ele está fazendo um "regime" e strangeiro".

É importante notar, primeiramente, que estas tendências alteritáriasetnocêntricas são componentes identitários de todo ser humano. Elas serão desenvolvidas no decorrer da existência, umas mais do que outras, influenciando o grau de abertura da criança para lidar com a diferença, "como um fluxo, uma abordagem, não um armazenamento” (MARIELLE RISPAIL, 2011, p. 177). Portanto, focalizar a aprendizagem da alteridade para dificultar a propensão etnocêntrica humana deve ser uma escolha societal. Para Edgar Morin (1991, p. 77), é necessário: "se dar conta que todo conbecimento suporta não somente uma determinação ego-cêntrica, mas também determinacoôes geno-cêntricas (identidade familiar), etno-cêntricas (identidade étnica), sócio-cêntricas (identidade nacional), civilizacio-cêntricas (identidade de pertencimento a uma civilização), e que estas determinações podem ser conflituosas num mesmo espirito", o que incita a gerenciar as identidades plurais não para reduzi-las, mas para protegê-las. A seguir apresentamos os resultados obtidos com crianças dos dois grupos: turmas experimentais e turmas de controle (com ou sem projeto "Despertar para as linguas-culturas do mundo").

\subsection{TENDÊNCIAS ALTERITÁRIAS-ETNOCÊNTRICAS NAS TURMAS DE CONTROLE}

Embora os resultados tenham sido obtidos a partir de uma fraca taxa de retorno dos 100 questionários transmitidos aos pais (53\%), eles indicam que a grande maioria das crianças das duas turmas parceiras $(70 \%)$ era monolíngue e monocultural em francês, ou seja, que só tinham o francês como língua de comunicação em casa (apesar do fato desta língua de escolaridade apresentar obviamente uma extrema variabilidade linguístico-cultural em função das situações familiares). Esta fraca taxa de retorno pode ter origem na insegurança linguística dos pais e traduziria então: "a conscientização pelos locutores de uma distância entre o que eles falam e uma língua (ou variedade de língua) legitimada socialmente porque ela é a língua das classes dominantes" (PHILIPPE BLANCHET, 2016, p. 85). Porém, e na ausência de outra ferramenta ética de medida da realidade da pluralidade linguístico-cultural das famílias e das crianças, apenas os resultados obtidos a partir dos questionários foram levados em conta. As tendências dos discursos das crianças observados e gravados durante as sessões de leitura-debate neste grupo escolar se baseiam na análise de 53 interações verbais significativas. A particularidade destas turmas é que a maioria dos discursos é marcada pela tendência discriminante no último ano da Educação Infantil para se transformar no $1^{\circ}$ ano do Ensino Fundamental $1 \mathrm{em}$ discursos

\footnotetext{
${ }^{3}$ Em francês: "Origine étrangère"

${ }^{4}$ Kenzo confundiu "origine" com "le regime" e "étrangère" com duas palavras separadas com a conjunção de coordenação "et trangère". Mas, esta interpretação da criança é um jogo fonético.
} 
neutros ou não discriminantes. Todavia, a taxa elevada de discurso com tendência discriminante no $1^{\circ}$ ano da Educação Infantil indica que as representações etnocêntricas das crianças em relação a um Outro diferente (cor da pele) parecem já ser construídas e verbalizadas numa situação livre de comunicação como no caso da sessão de leitura-debate que deixa espaço para a livre espontaneidade das atitudes:

- Mathéo: O bebê é bizarro...

- Professora: O que é que é bizarro, Mathéo?

- Mathéo: Ué?? Porque é negro...

A tendência discriminatória observada na criança de 5 anos vem junto com uma ausência total de empatia em relação à criança discriminada. Tudo indica que a alteridade é desenvolvida em um processo educativo, como confirma David Lasagabaster (2006, p. 394): “as atitudes se aprendem”. Zakary não vai saber expressar o nível de discriminação realmente sofrido após a seguinte interação verbal. Até que ponto a própria professora é capaz de perceber este sofrimento?

- Lunaa (branca e loira): A mulher é igual que Mégane (aluna negra da outra turma);

- Léna (branca com cabelos castanhos): Ela tinha os cabelos da mesma cor que Mégane. Ela tinha a mesma cor de pele que Mégane.

- Lunaa: Como Zakary (mostrando com o dedo o colega que se chama Zakary).

Se para Mathéo a discriminação já está ligada ao que é estranho, ou seja, a expressão de uma antinorma, para Juliette, no próximo diálogo, a discriminação é mais cognitiva e funciona como um estereótipo já adquirido:

- Juliette: Ahh, tem gente que vem da França, tem gente que vem da América...

- Professora: Então, como você vê se elas vêm da América, se elas vêm da França? Será que está escrito na testa delas?

- Juliette: Quando a gente está bronzeado, quer dizer que a gente vem de um país que faz. muito calor.

Ora, este tipo de discurso com tendência discriminante desaparece totalmente nas interações verbais acerca dos mesmos livros no ano seguinte. Este desaparecimento é realizado em favor de um discurso com tendência neutra porque o outro discurso com tendência não discriminante se mantém com uma taxa relativamente equivalente àquela do ano anterior. Este resultado é ainda mais paradoxal já que as crianças não beneficiaram de nenhuma abordagem da diversidade através de um projeto como o "Despertarpara as línguas-culturas do mundo". Finalmente, a variação observada entre estes dois anos consecutivos pode ser gerada por um desengajamento das crianças da atividade pedagógica que se traduziria pela ausência de posicionamento individual, como indica o exemplo seguinte:

- Professora (lendo o livro): "Quando estou com frio, sou preto....".

- Nolann: Oh! Tá rimando!

${ }^{5}$ Em francês froid/noir [f̌wa] [nwas] 
No próximo diálogo, no momento em que Natan define a sua própria cor de pele, a sua professora $\left(1^{\circ}\right.$ ano de Fundamental I) parece intervir no discurso da criança e passa a corrigi-lo explicitamente, o que deixaria a entender que ela está tomando um posicionamento pessoal antidiscriminante:

- Natan: Sou mestiço.

- Professora: Mestiço não é uma cor.

Assim, ela emite uma contestação não discriminante diante de uma autocategorização a priori discriminante. Ora, a dualidade, até mesmo a ambiguidade, reaparece logo no seu discurso quando ela confirma o contrário enquanto Natan expressa o seu vínculo identitário:

- Natan: Eu sou mestico!

- Professora: Vocêe é mestiço, realmente.

- Natan: Com Nordine e Jasmine.

- Professora: Isso...

- Marouane: Eu também!

- Outro aluno (não identificado): E eu? E eu?

A indiferença da professora acerca destas reivindicações identitárias confirma não apenas o motivo da sua correção anterior, que seria apenas lexical (ser mestiço não define uma cor específica), mas também suscita nas crianças um entusiasmo identitário transbordante e estimulante acerca de uma identidade fenotípica compartilhada apenas por alguns em detrimento, infelizmente, do resto da turma que não compartilha os mesmos traços físicos. Esta situação pedagógica que ignora as reivindicações identitárias em construção corre o risco de legitimá-las pela simples falta de um debate esclarecedor.

\subsection{TENDÊNCIAS ALTERITÁRIAS-ETNOCÊNTRICAS NAS TURMAS EXPERIMENTAIS}

Nas duas turmas experimentais, apenas os resultados de um grupo escolar foram conservados neste artigo em razão da alta taxa de participação mais significativa das crianças e das professoras que se disponibilizaram a implementar um projeto de "Despertar para as línguas-culturas do mundo" a partir do último ano da Educação Infantil. Os indicadores quantitativos expressos em porcentagens e os indicadores qualitativos que transcrevem e classificam os discursos das crianças em três categorias visam melhor compreender o postulado básico desta pesquisa que atribui ao "Despertar para as linguas-culturas do mundo" uma tarefa fundadora, propícia e ideal para a construção de uma competência alteritária que leva à competência (inter)cultural e desemboca na competência linguística. Assim, no desempenho total das sessões de leitura-debate, 124 interações verbais significativas foram coletadas nestas duas turmas do projeto "Despertar para as línguas-culturas do mundo". Porém, é necessário destacar uma diferença quantitativa notável já que 103 interações foram produzidas no último ano da Educação Infantil e apenas 21 no $1^{\circ}$ ano do Ensino 
Fundamental I. Essa disparidade importante é oriunda das dificuldades de sintonia com a filosofia educativa do projeto encontradas pelas equipes pedagógicas para prosseguir com o projeto "Despertarpara as línguas-culturas do mundo" logo no segundo ano da pesquisa. Estas duas turmas de um bairro popular representavam um quase equilíbrio entre as famílias se declarando monolíngue e monocultural (53\%) e as famílias se declarando plurilíngues e pluriculturais (47\%). Importante notar, mais uma vez, que a baixa taxa de retorno dos questionários transmitidos aos pais $(24 \%)$ para determinar realmente as "línguas-culturas familiares" (QUADRO EUROPEU DE REFERÊNCIA PARA AS LÍNGUAS, 200; MICHEL CANDELIER, 2003B; MAROUSSIA RAVEAUD, 2006; STÉPHANIE CLERC, 2008; CHRISTIANE PERREGAUX ET ELIZABETH ZURBRIGGEN, 2012; MALIKA BENNABI BENSEKHAR, 2015) praticadas com as crianças, indicaria o forte sentimento de insegurança linguística destas famílias que, na maioria dos casos, são francoarabofones e/ou com nacionalidades diferentes. Embora este estatuto de "estrangeiro" não seja a única causa desta insegurança linguística dos pais, temos que concordar com Frédérique Giuliani e Jean-Paul Payet (2014, p. 15, nossa tradução) que diante da Escola: "todos os pais não são iguais frente a esta expectativa de participação, sobretudo declinada num registro civico. Em particular, os pais migrantes alofones ou oriundos da imigração, em razãa do seu estatuto de estrangeiro, não se acham autorizados nem legitimados para interpelar os representantes da instituição". Nestas duas turmas do projeto "Despertar para as línguas-culturas do mundo", o discurso com tendência não discriminante é amplamente dominante. Este discurso é significativo na medida em que ele é um posicionamento alteritário nítido da criança. Essa alta taxa de discurso com tendência não discriminante está alinhada com a alta taxa de discurso com tendência não discriminante das professoras destas turmas durante as sequências pedagógicas e didáticas. Não é de se surpreender que haja uma quase equivalência quantitativa e qualitativa das tendências presentes nos discursos das crianças e naqueles das suas professoras através de um fenômeno mimético: $55 \%$ de tendência não discriminante, $26 \%$ de tendência neutra e $19 \%$ de tendência discriminante. Este fenômeno cognitivo mimético entre a criança e a sua professora não anula a capacidade que a criança de 5 anos tem de expressar certezas identitárias que são formas autodiscriminantes subjacentes inquietantes. Essa autoexclusão infantil é tão preocupante quanto a exclusão de uma criança em relação a outra. Assim, às vezes, o posicionamento identitário da criança pode apresentar de forma precoce uma certa irredutividade apesar da existência de um contexto particularmente favorável na sala de aula para a expressão e aceitação da sua diversidade, como é o caso no diálogo seguinte ocorrido nesta turma ligada ao projeto "Despertar para as línguasculturas do mundo":

- Professora: Será que a gente ouviu alguns papais e mamães falando uma língua... hum... diferente daquela que a gente fala na sala de aula?

- Grupo: Sim!

- Enzo: Ela é italiana e meu pai ele é... bum...

- Pelou: Minha mãe, ela é espanhola.

- Idriss: Meu pai, ele é árabe!

- Enzo: Ele nasceu na Costa do Marfim!

- Ivanny: Minha mãe, ela é de Madagascar. 
- Professora: E então? E vocês?

- Ramzy: Eu sou árabe.

- Professora: E vocês nasceram onde?

- Grupo: Na França!!!

- Professora: Então, vocês são o quê?

- Grupo: Franceses!!!!

- Ramzy (sorridente, mas não convencido): bum...

Ainda que aderindo plenamente ao projeto "Despertarpara as línguas-culturas do mundo" cujo objetivo principal é a aprendizagem da diversidade e a possibilidade da criança expressar a sua complexidade multi-identitária, a professora não consegue conceber esta reivindicação ao direito de ter várias filiações e reprova até inconscientemente este desejo infantil de filiação a uma outra língua-cultura que não seja a de escolaridade, ou seja, a dominante e do país natal. É, portanto, paradoxal que uma educadora preparada exija da criança plural escolher um "campo" identitário a partir dessa noção restrita da nacionalidade. Para Christa Preissing (2006, p. 20): "Se tiverem diferenças importantes entre a sua cultura familiar e a sua cultura do espaço de acolhimento, a criança vai ficar perturbada. O que está em jogo é saber se a criança pode se sentir pertencendo às duas culturas, ou se a filiação a uma se faz em detrimento da outra”. Reencontra-se esta noção no raciocínio da professora no diálogo seguinte, assim como a mesma certeza identitária da criança de 6 anos $\left(1^{\circ}\right.$ ano Fundamental I):

- Joulia: Eu, eu não sou francesa não.

- Professora (formadora de professores): Você nasceu na França?

- Joulia: Não.

- Professora: Você nasceu onde?

- Joulia: Na Arábia.

- Professora: Em que país?

- Joulia: Na Tunísia.

- Professora: Certo.

- Maëlys: Eu, eu não sou Francesa também.

(de repente, outras crianças levantam o dedo para falar e confirmar aparentemente $\mathrm{o}$ mesmo sentimento de filiação não francesa. A professora então muda de assunto sem nenhuma transição).

Um projeto como o "Despertarpara as línguas-culturas do mundo" é sociodidático por definição já que a "sociodidática é uma didática que fala em primeiro lugar daqueles que aprendem antes de se perguntar o que vamos ensinar" (MARIELLE RISPAIL, 2012, p. 67). Assim, através da verbalização das atitudes das crianças, a construção identitária pode tomar formas discriminantes quando um categoriza o outro. No diálogo seguinte, a convicção de Enzo não significa necessariamente uma ancoragem precocemente profunda (uma certeza absoluta) de um preconceito pois "Se essas categorias fossem apenas descritivas, isto não seria um problema. Mas, associamos a estas categorias, julgamentos e expectativas" (CHRISTA PREISSING, 2006, p. 24):

- Professora (se referindo ao menino da história): E ele está se perguntando: Será que sou árabe? Será que eu sou francês?

- Enzo: Ele é árabe! 
- Professora: No entanto, vocês me disseram que ele nasceu onde?

- Quentin: Na França!

- Professora: E então?

- Pelaou: Ah, então ele é francês.

- Jibril: Ele deve ser francês.

- Professora: Ele nasceu na França. Ele deve ser francês.

- Enzo: Ele é árabe.

As duas outras crianças parecem modificar suas perspectivas em função do discurso da professora. Apenas Enzo persiste na sua opinião. Esta categorização do outro é ofensiva quando emitida por um adulto, ainda mais por um educador, como estipula a lei francesa (Lei 2008-496, 2008, art.1): "Qualquer discriminação direta ou indireta fundada na filiação ou a não filiação, verdadeira ou suposta, a uma etnia ou uma raça é proibida no que diz respeito à proteção social, à saúde, às vantagens sociais, à educação [...]". Não se trata de aplicar esta lei ao contexto educativo, mas explicá-la aos educadores tanto escolares quanto familiares. Esse diálogo mostra o quanto essa tendência à categorização étnica discriminante já está presente na criança por reprodução certamente dos discursos captados e absorvidos por ela ao seu redor. O que está em jogo em um projeto de Educação para a diversidade linguístico-cultural não é a contestação prescritiva ou a proibição dessa tendência, mas a sua identificação pela Escola enquanto fenômeno precoce na criança ou fenômeno interiorizado no próprio educador. Assim, a partir dessa identificação, a professora pode reutilizar essa tendência com um objetivo educativo de (auto)transformação, não de (de)negação. O diálogo seguinte apresenta, desta vez, um discurso totalmente não discriminante das crianças apesar das orientações implícitas discriminantes da professora que mostra para a turma uma ilustração do livro "Amigos de todas as cores" utilizado nas sessões de leitura-debate:

Figura 2 - O recreio

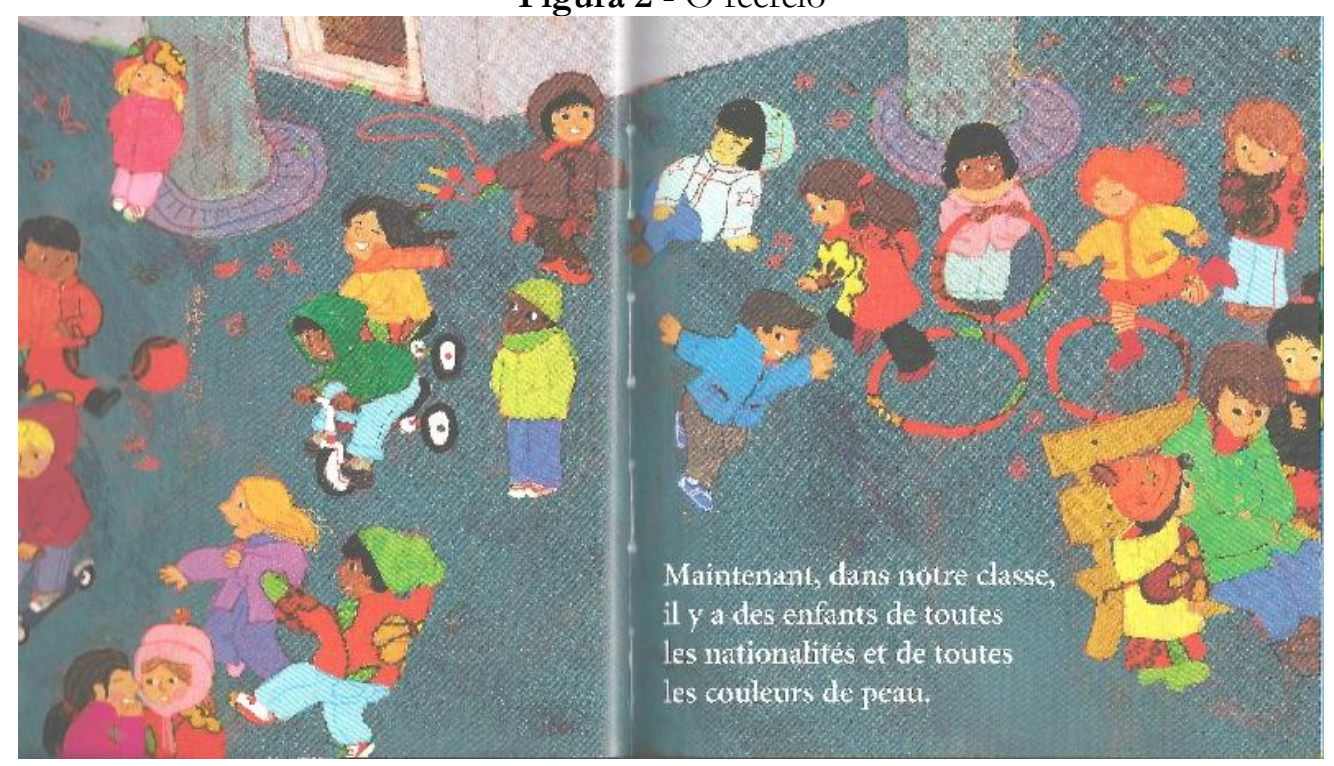

Fonte: Dolto, Faure-Poirée, 2009, p. 3-4 
- Professora: Então, será que esta quadra de recreação poderia ser a nossa, da nossa escola?

- Grupo: Não!

- Enzo: Não, porque tem bicicletas e bambolês!

- Professora: Tudo bem..., mas em relação às crianças que estão nessa quadra de recreação!? Na escola, será que tem apenas crianças da mesma cor?

- Enzo: De várias cores!

- Kenzo: Diferentes!

A insistência da professora não apenas revela a temática do livro, que deveria ser uma construção das crianças, como induz as suas respostas. De fato, para a professora de um projeto do tipo "Despertar para as línguas-culturas do mundo", existe geralmente um objetivo claro concreto e urgente a alcançar: a consciência antidiscriminatória. Porém, uma abordagem explícita com as crianças pode se tornar uma prescrição perniciosa já que a educadora pode não ter a certeza de que a regra ensinada tenha sido compreendida, muito menos interiorizada. Esta aprendizagem da diversidade é um processo que precisa ser co-construído a longo prazo e de acordo com uma progressão didática baseada em zonas de progressão sucessivas.

\section{CONSIDERAÇÕES FINAIS}

A construção de atitudes positivas das crianças em relação à diferençadiversidade tem como objetivo transformar o que lhes parece "diferente" e potencialmente rejeitável em algo "diverso" e potencialmente incorporável. Este artigo focou na construção atitudinal das crianças. Todavia, é evidente que esta construção é infinitamente complexa e é elaborada de maneira interdependente daquelas já concebidas pelos outros atores educativos familiares e escolares, inclusive e de forma simultânea, da construção atitudinal das outras crianças da sua turma e da sua escola. É a expressão oral das crianças e dos seus educadores que permite o acesso às atitudes mais interiorizadas, profundas e, às vezes, contidas. É, portanto, necessário pensar em um espaço onde a expressão oral da criança seja livre, sobretudo, nessas primeiras fases escolares, e em uma preparação para a diversidade linguística-cultural da professora que pode, assim, enfrentar, sem condenar ou estimular, situações pedagógicas conflituosas em razão de tendências discriminantes nascentes ou já existentes. No intuito de (re)pensar um ensinoaprendizagem de Língua estrangeira moderna inovador, é necessário refletir sobre as atitudes que a criança está construindo, individual e coletivamente, sobre a diferença e sobre a sua filiação identitária no decorrer da sua escolaridade. Este processo de construção passa pelas interações das crianças no seu dia a dia na sala de aula desde a Educação Infantil, seja no recreio, seja fora da escola. O papel da professora, embora fundamental, não é exclusivo. A criança entre 5 e 7 anos já demostra uma grande determinação no que diz respeito à sua disposição para descobrir ou rejeitar outra cultura-língua (Anne-Claude Feat-Feunteun, 2007, p. 45). Finalmente, em conclusão parcial das observações-intervenções realizadas com as crianças entre 5 e 6 anos nesta pesquisa dentro da Escola, isto é, dentro de um dos seus espaços sociais de aprendizagem, é possível realçar três recorrências 
pertinentes. A primeira recorrência é a "ancoragem" já nítida e profunda de tendências discriminantes da criança nesta faixa etária que se acentua por falta de contestação da professora, seja por falta de convicção pessoal, seja por falta de estratégia pedagógica. É possível agir de forma eficiente nos sistemas representacionais da criança em razão de uma construção ainda recente e em fase de desenvolvimento. Por outro lado, esta intervenção é bem mais complexa no que diz respeito às professoras em razão de sistemas mais antigos, ou seja, interiorizados há mais tempo. A segunda recorrência pertinente é a "submissão" da criança discriminada, intencionalmente ou não, pelo próprio grupo, apesar da figura simbólica paterna ou materna protetora do(a) professor(a). Embora esta submissão aparente (ausência de reação da criança discriminada) possa se configurar como real (interiorização e aceitação da discriminação) ou imaginária (incapacidade cognitiva e/ou emocional de tratar a discriminação como ofensa), a ausência de resposta, verbal ou não-verbal, é não apenas a expressão de um acordo tácito que a criança discriminada fornece para a criança discriminante, mas também a expressão do abandono da figura simbólica protetora na sala de aula. Enfim, a terceira e última recorrência pertinente, a "ingenuidade conceitual" da criança, tem relação direta com o estágio de desenvolvimento pré-operatório. De fato, a criança nem sempre parece ter a capacidade de entender os sentidos implícitos dos discursos da professora ou do discurso dos suportes didáticos apresentados. Não é a "ingenuidade" em si que é preocupante, e sim a dificuldade do adulto educador de adequar o seu discurso à capacidade de compreensão da criança. Todavia, é essencial ressaltar que uma minoria de crianças nesta faixa etária já demostra uma evidente precocidade no uso de estratégias de comunicação a fim de proteger a sua imagem social numa situação discriminadora que elas produziram. Seria necessário saber, neste caso, se a criança discriminadora vivencia um processo empáticoperverso com a outra criança discriminada ou um processo de transgressão consciente de uma regra social já internalizada e que pode expô-la a um castigo.

Uma característica marcante da criança nesse estágio de desenvolvimento é verdadeiramente o advento da linguagem que está em efervescência constante. Paradoxalmente, a vida escolar vai ensinar para a criança que a sua produção oral não é livre, nem espontânea, mas, pelo contrário, que ela deve estar estritamente submetida às regras escolares e da professora. Ora, antes mesmo de visar uma educação para as línguas-culturas, é fundamental almejar uma educação global para a linguagem e para as linguagens. Isto significa estimular a expressão oral da criança no respeito absoluto e necessário pela sua escuta. Escutando verdadeiramente as crianças, o educador poderá melhor discernir as atitudes incipientes, desarmar a tendência egocêntrica inerente a este período da infância e ensinar a empatia que é a chave para que a criança compreenda e desenvolva a alteridade. Afinal, as crianças estarão dispostas a descobrir um outro locutor e uma outra "cultura-língua" se o adulto educador demonstrou, para com elas, a mesma curiosidade e o mesmo respeito em classe. Este parece um caminho de intervenção atitudinal que inaugura uma outra forma de lidar com a diferença. 


\section{REFERÊNCIAS}

BENNABI BENSEKHAR, Malika et al. Les pathologies du langage dans la pluralité linguistique. Paris: Presses Universitaires de France, 277 p., La psychiatrie de l'enfant, n'1, vol. 58., 2015.

BLANCHET, Philippe. Discriminations : combattre la glottophobie. Paris: Textuel, 2016.

BRUN, Éric. Sur l'évolution altéritaire-ethnocentriste en classe de cycle 2 dans le cadre d'un projet d'Éveil aux langues-cultures du monde: une analyse comparative longitudinale à travers l'expression orale. 2015, 338p. Tese de Doutorado. ESPÉ d'Aix en Provence: Université d'Aix Marseille ; École doctorale 356 Cognition, Langage, Éducation ; Laboratoire Parole et Langage, 2015.

CANDELIER, Michel et al. Cadre de Référence pour les Approches Plurielles des Langues et des Cultures - Compétences et ressources. Strasbourg: Éditions du Conseil de l'Europe. 2012.

CANDELIER, Michel et al. Janua Linguarum, La porte des langues, l'introduction de l'éveil aux langues dans le curriculum. CELV. Strasbourg: Éditions du Conseil de l'Europe, 2003b.

CANDELIER, Michel et al. L'éveil aux langues à l'école primaire - Evlang: bilan d'une innovation européenne. Bruxelles: De Boeck, 2003 a.

CLERC, Stéphanie. Des représentations des langues familiales à leur prise en compte dans le système scolaire. Repères - Recherches en didactique du français langue maternelle, nº38, p.187-198. 2008.

CONSEIL DE L'EUROPE - UNITE DES POLITIQUES LINGUISTIQUES Cadre européen commun de référence pour les langues - apprendre, enseigner, évaluer. Paris: Les Éditions Didier, 2001.

DOLTO, Catherine, FAURE-POIREE, Colline. Des amis de toutes les couleurs. Paris: Giboulées, 2009.

FEAT-FEUNTEUN, Anne-Claude S'approprier des langues à l'école. Une co-construction perceptive chez des enfants de cinq à sept ans. Tours: Université François Rabelais, 2007.

GIULIANI, Frédéric ; PAYET, Jean-Paul Introduction. Les logiques scolaires de la proximité aux familles, Education et sociétés, De Boeck Supérieur, n³4, p.5-21. 2014.

KEMOUN, Hubert ; HEITZ, Bruno. L’oeuf du coq. Bruxelles: Casterman, 2005 
KERVRAN, Martine Les langues du monde au quotidien Cycle 2 : Observation réfléchie des langues. Rennes: Canopé - CRDP, 2012.

$\mathrm{KOCH}$, Miriam ; Makarius, Catherine. 2008. Le voyage de Solo. Paris: Editions Sarbacane.

LASAGABASTER D., Les attitudes linguistiques: un état des lieux, Revue de didactologie des langues-cultures et de lexiculturologie vol 4, n 144, 2006, p. 393-406.

MINISTERE DE L'EDUCATION NATIONALE Repères \&o références statistiques Sur les enseignements, la formation, et la recherche. Courbevoie: Direction de l'évaluation, de la prospective et de la performance (DEPP), 2016.

MORIN, Edgar. La Méthode: Les Idées. Leur habitat, leur vie, leurs mours, leur organisation. Paris: Seuil, 1991.

PERREGAUX, Christiane ; ZURBRIGGEN, Elizabeth. Quand le post-it favorise les liens entre la famille et l'école: l'exemple des sacs d'histoires. In: BALSIGER, Claudine et al. Éveil aux langues et approches plurielles - De la formation des enseignants aux pratiques de classe. Paris: L'Harmattan, 2012, p. 175-192.

PREISSING, Christa ; WAGNER, Petra Les tout-petits ont-ils des préjugés? : Education interculturelle et antidiscriminatoire dans les lieux d'accueil. Ramonville Saint-Agne: Erès, 2006.

PRESIDENCE DE LA REPUBLIQUE FRANÇAISE Lei n 2008-496 de 27 maio 2008 sobre diversas disposições de adaptação do direito comunitário no âmbito da luta contra as discriminações. NOR: MTSX0769280L, 2008). Versão consolidada em 12/11/2016. Disponível em: $<$ https://www.legifrance.gouv.fr/affichTexte.do?cidTexte=JORFTEXT0000188 77783> Acesso em 12/11/2016.

RAVEAUD, Maroussia De l'enfant au citoyen: La construction de la citoyenneté à l'école en France et en Angleterre. Paris: Presses Universitaires de France, 2006.

RISPAIL, Marielle, Etudier un corpus d'interactions verbales: questionnement entre incertitudes et certitudes, IN: BLANCHET, P. ; CHARDENET, P. Guide pour la recherche en didactique des langues et des cultures, Paris: Editions des archives contemporaines, 2011. p. 168 à 179.

RISPAIL, Marielle. Interroger la sociodidactique: faux-semblants, résistances et orientations. In: ABBES ATTICA Yasmine ; KEBBAS Malika. Reconfiguration des concepts - Pour une réflexion épistémologique et méthodologique en sociolinguistique et en sociodidactique. Socles, $\mathrm{n}^{\circ}$ 1, 2012, p.63-84.

RUILLIER, Jérôme. Homme de couleur ! Vineuil: Éditions Bilboquet, 2011. 